\title{
The Study of Solar Monitoring System
}

\author{
Zhanlan Xie ${ }^{1, a}$, Wen Yang ${ }^{2, b^{*}}$, Xiaoyan Zhang ${ }^{2, \mathrm{c}}$ and Zhe $\mathrm{Li}^{2, \mathrm{~d}}$ \\ ${ }^{1}$ N0.170, Xincheng Avenue, South New Zone, Xining City, Qinghai Province, China \\ ${ }^{2}$ No.19, Chengxin Avenue, Jiangning District, Nanjing City, Jiangsu Province, China \\ acwowo@163.com, byangwen@sgepri.sgcc.com.cn, ${ }^{\mathrm{a}}$ zhangxiaoyan@sgepri.sgcc.com.cn, \\ lizhe6@sgepri.sgcc.com.cn
}

\begin{abstract}
Keywords: Photovoltaic, Solar Monitoring, System Structure, Communication Mode
Abstract. Vast photovoltaic powers connect into power distribution network Distribution Network. These PVs are large in quantity and scattered, make grid difficult in monitoring, which will bring challenge to the safety and stabilization of power grid. It is very necessary to get related monitoring data of PVs. The solar monitoring-control system in this paper can realize the real-time monitoring and control of photovoltaic power plant, and realize the accurate, efficient collection and remote transmission.
\end{abstract}

\section{Introduction}

The energy crisis and environmental issues become the constraints of social and economic development, vigorously develop new energy has risen to the national energy development strategy, and become an important area of the development of smart grid technology. China is a big country of energy consumption, so, we attach greater importance of the development of new energy, and develop a grand new energy development planning. In "renewable energy long-term development plan" National energy board clearly demands that China's renewable energy consumption will reach $15 \%$ of total energy consumption by 2020. In September 2014, the National Energy Board issued "further implementation of distributed photovoltaic power generation policy" to strengthen the promotion of distributed PV applications. All aspects of policy support, for the photovoltaic and equal distribution of new energy for large-scale applications to provide a strong impetus.

Distributed power supply has been widely concerned by the whole society because of its advantages of environmental protection, clean and renewable. There is no mechanical moving parts, no consumption of fuel and no greenhouse gases in the course of photovoltaic power generation. Photovoltaic power generation has the characteristics of no noise, no pollution. Solar is the energy resources without region limit, which is widely distributed and inexhaustible. So PVs are welcome.

With the large scale application of distributed PV, the proportion of distributed energy photovoltaic grid in the future will be bigger and bigger. Vast photovoltaic powers connect into power distribution network Distribution Network. These PVs are large in quantity and scattered, make grid difficult in monitoring, which will bring challenge to the safety and stabilization of power grid.

In the traditional sense, the monitoring of photovoltaic power generation system is generally based on close range, that is, close monitoring[1]. This monitoring method is mainly through the liquid crystal display to know all kinds of power plant operation parameters (PV array voltage, battery voltage, battery charge and discharge current, etc.) and environmental parameters (such as ambient temperature, solar radiation intensity, etc.). Maintenance personnel must observe in the field, and continuously monitor the display of the monitoring device, make the appropriate treatment, and use manual methods to control the system's various state and parameters, including the modification parameters and viewing parameters[2]. This approach requires that each maintenance point is equipped with a certain maintenance personnel, these maintenance personnel operate on job sharing. The number of PV power station is big, and the natural environment is relatively poor, this method has the defects of "low efficiency with high cost", and causes a large number of data and information redundancy and inconsistency. Due to the influence of the photovoltaic power generation to the distribution network, it is necessary to construct a photovoltaic power generation monitoring system. 


\section{Characteristic analysis of photovoltaic power generation system}

Through investigation and analysis, we found that the photovoltaic power generation system has the following characteristics:

Photovoltaic power generation systems generate a large number of data in all the time, mainly including the various operating state, such as photovoltaic array voltage, PV array current, battery terminal voltage, battery temperature, ambient temperature, wind speed, light intensity, etc.. At the same time, all kinds of on-line application programs are used to analyze the reliability and stability of the system, and provide a lot of relevant information to the dispatcher. These applications include state estimation, online calculation, stability analysis, etc.. At the same time, all kinds of offline analysis and calculation program running on the other departments of the photovoltaic power generation system will produce a large amount of data.

The data format of photovoltaic power generation system is varied. In photovoltaic power generation system, the data is stored in real-time database in order to meet the requirements of real-time performance; while in other departments, the data may be stored in a variety of relational database text files and binary files. All these data sources are often independent of each other; it is difficult to achieve data sharing. Especially the operating status of the PV system cannot be used by various offline applications, resulting in a large number of data redundancy and inconsistency of data.

The historical data of PV power generation system is significant. Photovoltaic power generation system is a continuous system. The status of the system within a certain time will affect the subsequent state or at least reflect the trend of the system in a certain period of time. So the accurate prediction of system state will greatly promote the operation and control of photovoltaic power generation system.

Photovoltaic power generation systems and systems of other industries need to share data. For example, the climate is a very important factor in the generation of photovoltaic power generation systems, especially in the case of continuous rainfall or snowfall. But at present, due to the meteorological data is not sufficient or difficult to obtain, the climate factor is not even fully thought out in PV energy production. If we are able to obtain continuous meteorological data from the meteorological department, power generation forecasting will be more accurate and credible, and help to the energy dispatch.

With the popularization of the network, the demand for the online inquiry and report form is more urgent. At present, if the dispatch staff needs the report of the average power generation in the past month, the specific technical personnel must first collect data from the control center, figure out, preparation of the statements, finally sent to the dispatch staff after print. This process is very time consuming and inefficient. With the development of the network and various software tools, users can query the data and information on their own and prepare the report according to their own preferences. To achieve such a function, the establishment of a unified data and information center is the foundation[3].

From the above that it is necessary to establish the integrated data and Information Center for the PV system, the PV monitoring system has been shown to be a complete solution for the construction of such a system.

\section{Solar Monitoring System}

According to the mode of communication, the overall structure of the photovoltaic monitoring system is divided into two types: wired remote monitoring and wireless remote monitoring. Wired remote monitoring achieves the long-distance signal transmission by communication bus, but the distance is limited, even uses the line repeater. Especially the system is installed in remote areas, the wired remote monitoring is not realized. Wireless remote monitoring is not restricted by region and distance, especially in remote areas.

The application of the wire data communication technology includes: (1) using industrial bus, such as 485 bus, CAN bus to communicate the lower computer (DSP, microcontroller, industrial control, 
etc.) and host monitor computer; (2) using modem through to achieve with the public telephone network; (3) using Internet and the former two ways to achieve, this mode has wider range of applications, can achieve longer distance.

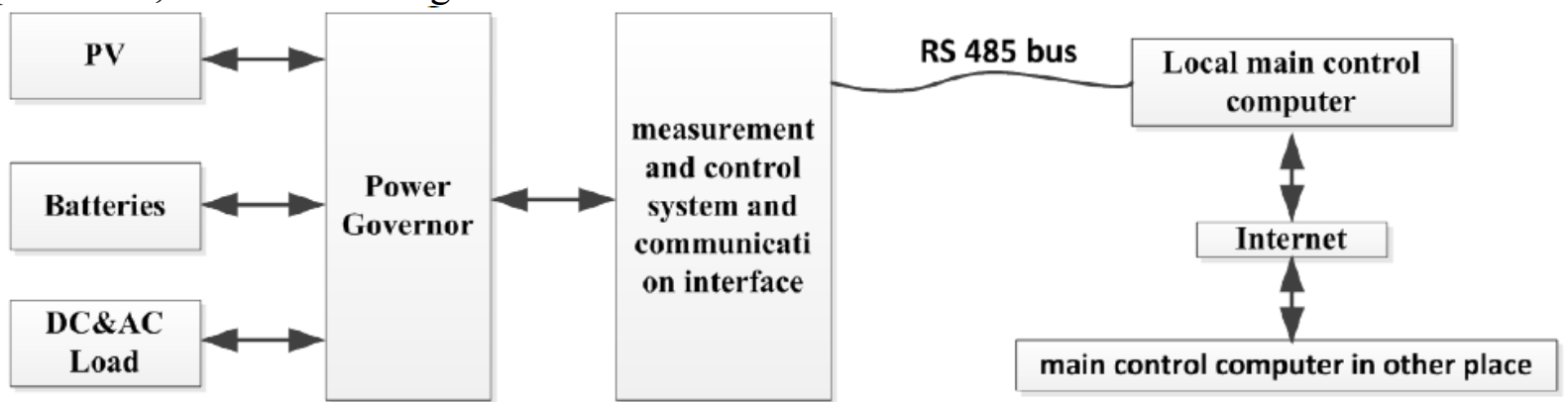

Fig. 1 Wired remote monitoring system with internet

Fig. 1 shows a wired remote PV monitoring system with RS485 industrial bus and Internet. RS485 can realize the network monitoring among several local PV systems, then connect the local network computer by conversion interface, realize remote monitoring by Internet.

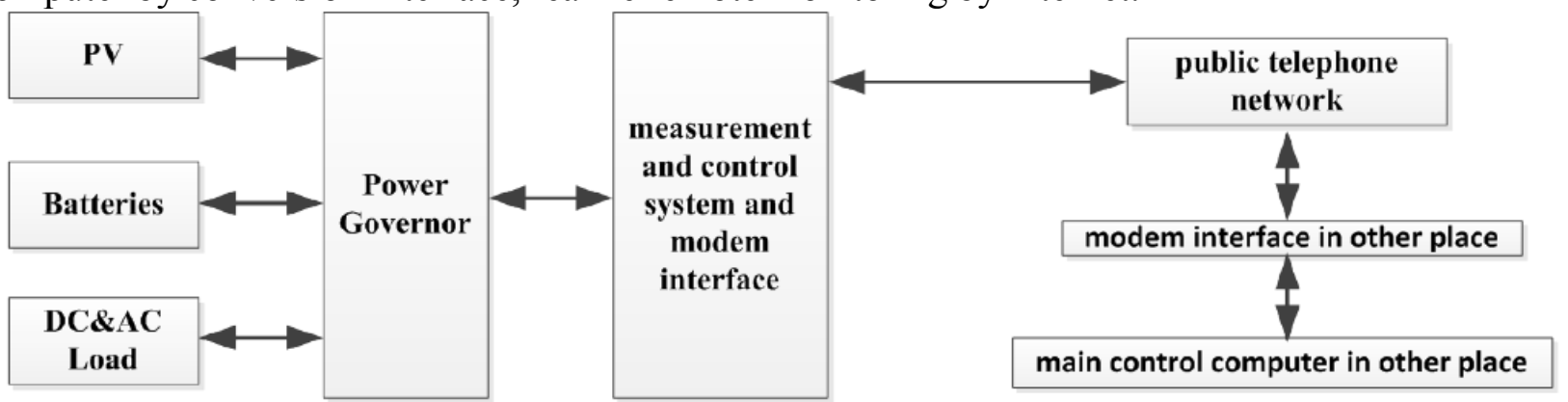

Fig. 2 Wired remote monitoring system with Public Switched Telephone Network

Fig. 2 shows a wired remote PV monitoring system with Public Switched Telephone Network and Modem. This system through Modem and with the help of Public Switched Telephone Network to realize point-to-point wired remote monitoring.

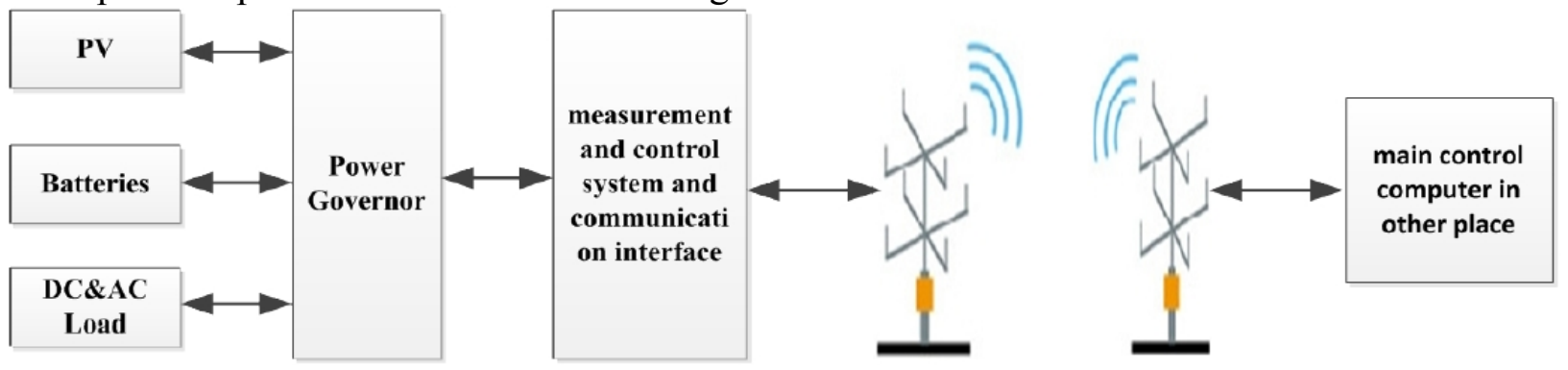

Fig. 3 PV monitoring system with relay station

Wireless data communication technology is mainly based on the relay transmission technology of microwave station or artificial satellite, such as the use of mobile communication signal frequency band for transmission, such as Fig. 3. At present, a lot of solar photovoltaic power stations on the mobile stations achieve remote data communication in west China.

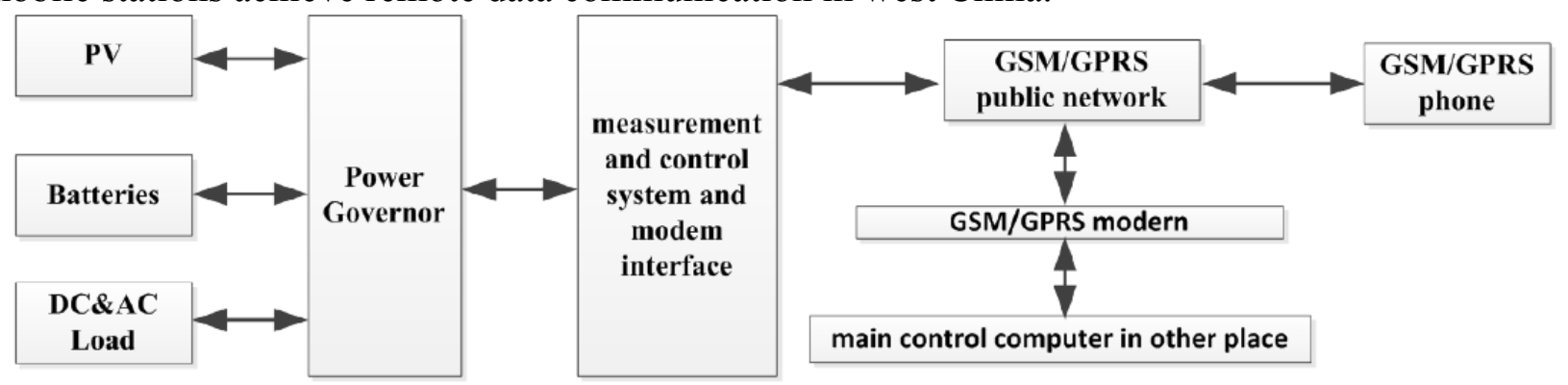

Fig. 4 PV monitoring system based on Wireless communication network 
Fig. 4 shows a PV monitoring system based on GSM/GPRS wireless mobile communication network. The remote data communication of this system is realized by the application of the GSM/GPRS data communication service or SMS (Short Message Service).

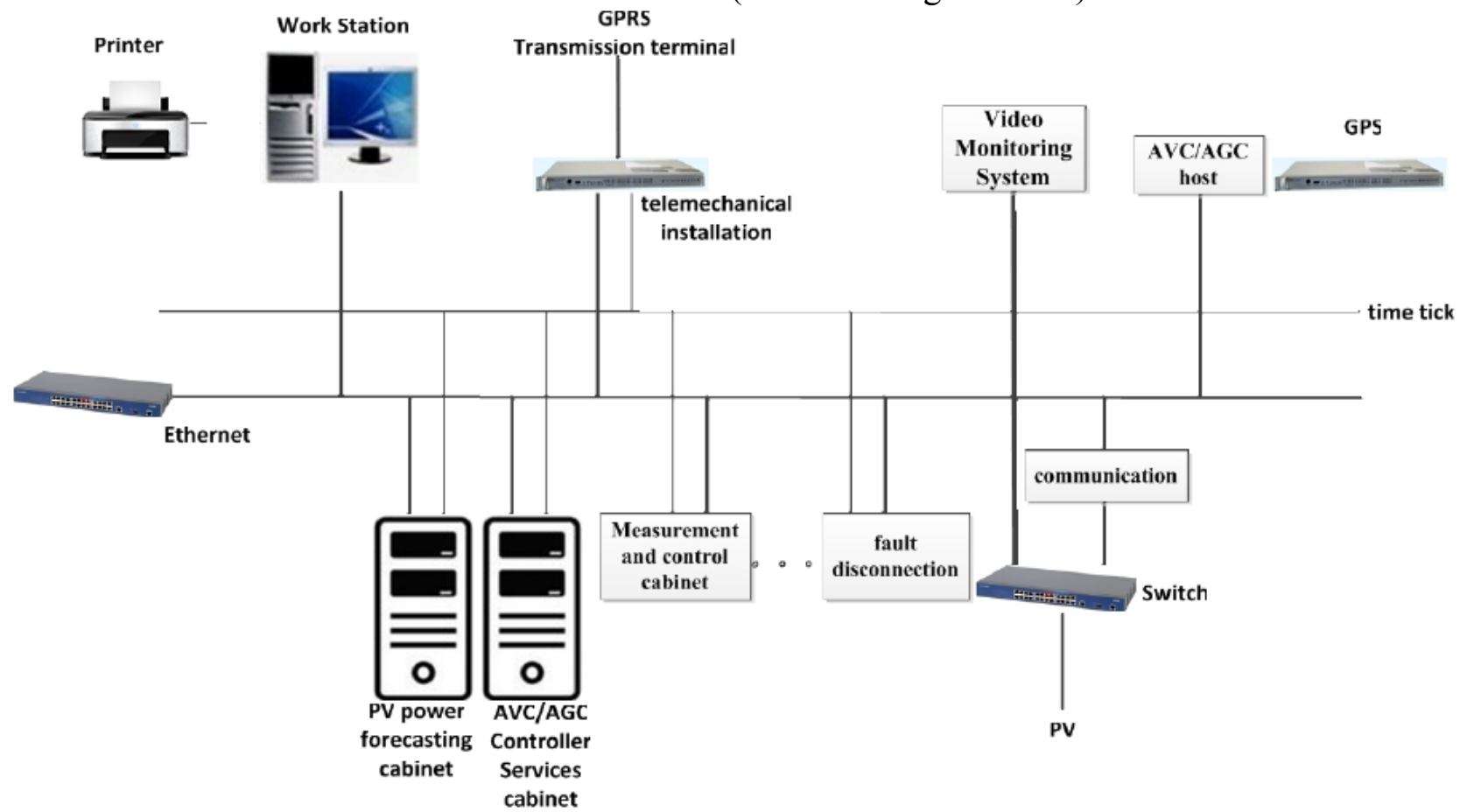

Fig 5 Overall topological structure diagram of PV monitoring system

PV monitoring system realizes real time monitoring (SCADA) of photovoltaic power plant. Fig. 5 shows the overall topological structure diagram of PV monitoring system. This system is equipped with application server, power prediction server and interactive workstation. Monitoring functions include data acquisition and processing, control operation, photovoltaic power generation unit monitoring, alarm processing, image generation and display, on-line calculation, data interface, clock synchronization, man-machine communication, self-repairing, etc.. According to the order of operator input, the monitoring system can realize the normal operations (as circuit breaker, constant value, press board, switch, etc.) and other necessary operations. Execution results of operating control will feed back to associated equipment drawings. These executions generate normal (or abnormal) execution reports, the reports can display and printing. In order to ensure the safe and reliable operation, the whole system has strict safe protective measures, can realizes the closing block of operate exit and records the operation projects and time.

\section{Conclusions}

Solar photovoltaic energy system is a kind of rising green energy, which has a broad outlook for development. Solar photovoltaics are scattered distributed, so the cost of PV data monitoring and maintenance is high. It is very necessary to get related monitoring data of PVs. The solar monitoring-control system in this paper can realize the real-time monitoring and control of photovoltaic power plant, and realize the accurate, efficient collection and remote transmission.

\section{Acknowledgements}

This work was financially supported by the "Large-scale integrated application of distributed photovoltaic systems". 


\section{References}

[1] Cristaldi L, Faifer M. Ferrero A, et al. On-line monitoring of the efficiency of Photo-Voltaic panels for optimizing maintenance scheduling [J],Instrumentation and Measurement Technology Conference(I2MTC), 2010, pp.564-571.

[2] Othman N A, Damanhuri N S, IBRAHI MI R, et al. Automated monitoring system for small scale dual-tariff solar PV plant in UITM Palau, Proceedings of the World Congress on Engineering, London,2010.

[3] Zahran M, Ati A Y, Ai-Hussai N A, et al. Lab View based monitoring system applied for PV power station, Proceedings of the $12^{\text {th }}$ WSEAS International Conference on Automatic Control Modeling \& Simulation, 2010. 